\title{
Uma perspectiva psicossocial \\ da sintomatologia depressiva na adolescência
}

\section{A psychosocial perspective of depressive symptoms in adolescence}

ThaisAraújo Aragão ${ }^{1}$

M aria da Penha de Lima Coutinho ${ }^{2}$

Ludgleydson Fernandes deA raújo ${ }^{3}$

Alessandra Ramos Castanha ${ }^{4}$

${ }^{1}$ Centro deCiências

HumanaseNaturais,

UniversidadeFederal do

Espírito Santo. Av. Fernando

Ferrari $s / n$, Goiabeiras.

29060-900 Vitória ES.

thaisaragao7@gmail.com

2 UniversidadeFederal da

Paraíba.

${ }^{3}$ Universidade Federal do

Piauí.

${ }^{4}$ Universidade de São

Paulo.
Abstract This study aimed at understanding the social representations (SR) of depression amongadolescents on high school level. Two hundred and twenty-two (222) adolescents of both sexes (53\% male and $47 \%$ female), aged between 14 and 19 years and attending the first, second and third grades of high school participated in thestudy. Theinstrumentsused were: the Beck Depression Inventory (BDI) for selecting the sample, using 17 as a cut point. The adolescents who achieved this score were invited to participate in the second part of this study consisting of semi-structured interviews and application of Free Association Tests with the stimulus words: depression, depressed person and me. It was verified that the adolescents anchored their SR of depression as synonym for pain, grief, misfortune, hatred, death, dis couragement, anxiety, solitude and tears. The SR elaborated by the social actors of this study revealed a similarity with the conception/description, as described in psychiatry. The purpose of this study be sides helping to understand the suffering provoked by depressive symptoms is to contribute to a better quality of life of these adolescents.

Key words Social representations, Depression, Adolescence
Resumo Este trabalho objetivou apreender as representações sociais (RS) da depressão entre adolescentes inseridos no contexto do ensino médio. Participaram 222 adolescentes, de ambos os sexos (53\% masculino e 47\% feminino), com idades entre 14 e 19 anos, que cursavam da primeira a terceira série do ensino médio. O s instrumentos utilizados foram: inventário de Beck para medir depressão (BDI), que serviu de screening na seleção da amostra, sendo 0 ponto de corte utilizado de 17. Os adolescentes que obtiveram este somatório foram convidados a participar do segundo momento do estudo, no qual foram aplicados os testes deassociação livre de palavras com os estímulos indutores: depressão, pessoa deprimida e eu mesmo, posteriormente as entrevistas semi-estruturadas. Verificou-se que os adol escentes ancoraram suas RS da depressão como sinônimo de dor, mágoa, infelicidade, ódio, morte, desânimo, angústia, solidão e choro. As RS elaboradas pelos atores sociais desta pesquisa revelaram uma similitude com a concepção/descrição, tal como descreve a nosologia psiquiátrica. A partir desses resultados, pretende-se, além de compreender o sofrimento provocado pela sintomatologia depressiva, contribuir para uma melhor qualidade de vida desses adolescentes.

Palavras-chave Representações sociais, Depressão, Adolescência 
Introdução

Têm-se observado no nosso cotidiano um número cada vez maior de pessoas de todas as idades (crianças, adolescentes, adultos e idosos) que se queixam de um mal-estar generalizado. Quando questionadas com maior profundidade sobre estas queixas, as respostas comumente encontramse associadas à mudança de humor (tristeza, choro, irritabilidade), sem causa aparente, diminuição por inter esse de atividades que até então eram propiciadoras de prazer, diminuições de energia física e mental, distúrbios de sono, alimentação, entre outras perturbações. De modo geral, essas perturbações são indicadores da depressão considerada a grande vilã do final do século XX e que, segundo Coutinho ${ }^{1}$, é uma das maiores ameaças do equilíbrio do bem-estar do novo milênio.

Deacordo com a Organização M undial deSaúde (OM S), desde a década de 1990, a depressão vem ocupando uma posição de destaque no rol dos problemas de saúde pública, considerada a quarta doença mais cara de todas as doenças em todo mundo e que, até 0 ano de 2010, só perderá o primei ro lugar para as doenças isquêmicas cardíacas graves. Ainda segundo a OM S, esta síndrome, no ano de 2020, será a segunda moléstia que mais afetará os países desenvolvidos e a primeira em países em desenvolvimento ${ }^{2,3}$.

A depressão é uma doença com um índice bastanteelevado $0^{4,5}$, ocorren do em qual quer idade, sem diferenças raciais ou geográficas. Essa constatação é corroborada por W innicott ${ }^{6}$, pois para ele, longe de ser uma doença rara, a depressão é um estado bastante presente, afetando desde crianças bastante pequenas a adolescentes, chegando até os adultos. Teoricamente, os quadros da depressão possuem esquemas estruturais bastante claros. Na prática, porém, nem sempresão nítidos, devido à pluralidade desua etiologia eà complexidade de sua sintomatologia, quedificultam o reconhecimento precoce, prejudicando, conseqüentemente, o desenvolvimento preventivo do diagnóstico/prognóstico.

A adolescência pode ser destacada por algumas características, como o desenvolvimento do autoconceito, auto-estima e deconceitosmais complexos. É uma fase caracterizada pelo aumento das responsabilidades sociais, familiares e profissionais. Pode ser considerada como um período de grandeaprendizagem denormas, conceitos sociais e morais, mesmo que às vezes sejam contrariados e violados no sentido da experimentação dos limites. Também é uma fase de acentuadas mudanças biológicas e hormonais, que proporcionam, muitas vezes, dúvidas, inquietação emudanças decom- portamento em relação aos pares sociais (amigos) efamília?.

Duggal et al. ${ }^{8}$ afirmam que de 3 a $15 \%$ dos adolescentes apresentam sintomas depressivos moderados e severos, que por muitas vezes se assemeIham aos apresentados pelos adultos; porém, existem importantes características que são típicas do transtorno depressivo nessa faixa etária, tais como a irritabilidade, a instabilidade, crises de explosão, raiva e graves problemas de comportamento, especialmente 0 uso abusivo de substâncias como álcool e outros tipos de drogas. Kazdin e M arciano ${ }^{9}$ afirmam que mais de $80 \%$ dos jovens deprimidos apresentam humor irritado e ainda perda de energia, apatia e desinteresse importante, retardo psicomotor, sentimentos de desesperança, culpa, perturbações do sono, alterações de apetite e peso, isolamento e dificuldade de concentração. Outras características próprias da depressão nesta fase da vida são os prejuízos no desempenho escolar, a baixa auto-estima, isolamento social, alterações no relacionamento familiar e 0 aumento das idéias e tentativas de suicídio ${ }^{10}$.

Segundo Ballone ${ }^{11}$, de modo geral, os adolescentes deparam-se com várias situações novas e pressões sociais (o mundo moderno está se tornando cada vez mais complexo, competitivo, exigente), tendo dificuldades para lidar com as necessidades de adaptação com que se deparam diariamente, favorecendo assim condições próprias para que apresentem flutuações do humor e mudanças expressivas no comportamento. As síndromes depressivas caracterizam-se por uma multiplicidade de reações afetivas, instintivas, cognitivas, alterando a maneira como a pessoa percebe 0 mundo e sentea realidade, entendeas coisas, manifesta emoções, sente a disposição e o prazer com a vida.

Resmini ${ }^{12}$ afirma que 0 adolescente possui tendência natural para comunicar-se através da ação, em detrimento da palavra. Por isso, na busca de uma solução para seus conflitos, os jovens podem recorrer às drogas, ao álcool ou à sexualidade precoce ou promíscua na tentativa de aliviar a dor ou reencontrar a harmonia infantil perdida. Enraivecidos podem orientar-se para comportamentos agressivos e destrutivos contra a sociedade. É comum observarmos um jovem manifestar sua depressão através de uma série de atos anti-sociais.

Quando uma doença surge na vida de um indivíduo, traz consigo alteraçõesetransformações não só no organismo como também no modo de vida e nas relações sociais desse indivíduo. Quando se trata de uma sintomatologia como a depressão em adolescentes, estas implicações são bastante sérias, uma vez que, não diagnosticadas satisfatoriamente 
no início do seu desenvolvimento, podem provocar seqüelas bastante fortes. De fato, observou-se nas duasúltimas décadas um aumento muito grande do número de casos de depressão com início na infância ena adolescência. Para conviver com essas implicações, os indivíduos constroem representações sociais que lhes auxiliam na atribuição desentido para orientar seus comportamentos no decorrer da experiência com a doença ${ }^{1}$.

Para Doise ${ }^{13}$, a utilização da teoria das representações sociais no diagnóstico psicossocial ébastante útil na medida em que se lida com um marco conceitual que envolve tanto o nível intrapessoal de análise como o interpessoal e o grupo; desta forma, é possível partir das representações pessoais de objetos sociais para um exame das cognições no nível grupal, que permitam ao pesquisador a apreensão dos aspectos compartilhados de uma representação.

As representações sociais são um produto da atividade humana, elaboradas a partir da interação sujeito/objeto social; neste estudo (adolescentes/ depressão), o coletivo constrói uma realidade particular que determina os comportamentos e direciona a comunicação entre os grupos nas relações interpessoais da vida cotidiana, "à medida que remodela e constitui os elementos do meio ambiente em que o comportamento teve lugar" ${ }^{14}$. N esse sentido, épossível verificar-secomo éelaborada a sintomatologia da depressão no nível cognitivo, observar-secomo esta representação é partilhada por esses indivíduos, como eles transformam o não inteligível em inteligível para os membros do grupo, possibilitando uma interação social integrada.

Acessar a representação social da sintomatologia da depressão é tentar não só compreender as formas que os indivíduos utilizam para criar, transformar e interpretar essa problemática vinculada à sua realidade, mas também conhecer seus pensamentos, sentimentos, percepções e experiências de vida compartilhadas por crenças, atitudes, valores e informações, destacadas nas modalidades diferenciadas de comunicação, de acordo com a classe social a que pertencem. Tentar conhecer o que existe nas mentes dos indivíduos, prolongando-se para além das dimensões intrapsíquicas e concretizando-seem fenômenos sociais possíveis deserem identificados e mapeados ${ }^{1}$.

Nos dias atuais, o desafio quanto ao reconhecimento precocee suas formas de apresentação, principalmente na criança e no adolescente, continua objeto de discussões por parte dos profissionais que lidam direta ou indiretamente com o proble$\mathrm{ma}^{15,16}$. Da mesma forma, Angold e Costello ${ }^{17} \mathrm{Co}-$ mentaram a não-existência de uma definição empírica e amplamente aceita sobre esse quadro.

A relevância deste artigo pauta-se na busca de novas formas de conhecimento, por meio do referencial teórico das representações sociais, de uma temática prolixa e plural como é o caso da depressão, que precisa ser melhor discutida e trabalhada no âmbito da atuação de profissionais da saúde coletiva e áreas afins, que venha contribuir para a elucidação e a compreensão da referida sintomatologia. Partindo desses pressupostos, assim como da verificação do interesse que o objeto de pesquisa tem despertado, em função do seu valor intrínseco, da sua relevância cultural e espessura social, esta investigação objetivou apreender as representações sociais da depressão no coletivo de adolescentes inseridos no contexto do ensino médio da rede pública da cidade de João Pessoa, Paraíba.

\section{M étodo}

\section{Participantes}

A pesquisa foi desenvolvida em uma escola pública, localizada na cidade de João Pessoa (PB), escolhida tanto por suas semelhanças estruturais (pela disponibilidade de número significativo de estudantes do ensino médio e a diversidade sociocultural), como pela abrangência sociodemográfica dos sujeitos ali inseridos. A amostra foi composta por 222 adolescentes; destes, 19 apresentaram a sintomatologia depressiva de acordo com o inventário de Beck para medir depressão (BDI) ${ }^{18}$, de ambos os sexos ( $53 \%$ masculino e $47 \%$ feminino), entre 14 e 19 anos, com média de idade de 17 anos ( $D P=3,67$ ) (que cursavam da primeira a terceira série do ensino médio).

\section{Instrumentos}

Inventário de depressão de Beck (BDI)

Tal instrumento é válido para medir a intensidade da depressão, podendo ser aplicado a sujeitos de 17 a 80 anos (embora também possa ser aplicado em faixas etárias inferiores e superiores a estas). Este inventário consiste em 21 grupos de afirmações, cada um com quatro alternativas, subentendendo graus crescentes de gravidade de depressão, com escores de 0 (zero) a 3 (três) ${ }^{19}$.

Teste de associação livre de palavras

0 teste de associação livre de palavras ${ }^{20}$ é um tipo de investigação aberta quese estrutura na evo- 
cação de respostas dadas a partir de um estímulo indutor (neste estudo, depressão, pessoa deprimida e eu mesmo), o quepermite colocar em evidência universos semânticos de palavras que agrupam determinadas populações. Esse instrumento já foi experimentado e validado em pesquisas realizadas sobre representações sociai ${ }^{21,1}$. Segundo Abric ${ }^{22}$, ele permite a atualização de elementos implícitos ou latentes que seriam perdidos ou mascarados nas produções discursivas. Os dados obtidos através do teste de associação livre de palavras constituem-se em respostas evocadas (ocasionalmente, palavras, expressões, frases) pelos atores sociais relativas às palavras indutoras.

\section{Entrevistas semi-estruturadas}

Foram utilizadas entrevistas semi-estruturadas, constituídas inicialmente de itens referentes à identificação sociodemográfica dos participantes, com o intuito de registrar dados como sexo, idade, escolaridade, e uma segunda parte composta por questões que foram formuladas tendo como pressupostos os objetivos da pesquisa, tais como: Fale sobre tudo o que vocêentende por depressão; D escre va 0 que sente uma pessoa depressiva; A depressão tem cura? Se sim, qual o tratamento?

\section{Procedimentos}

0 projeto foi enviado ao Comitê de Ética em Pesquisa com seres Humanos do CCS (Centro de Ciências da Saúde) da UFPB, para que as questões éticas fossem avaliadas, tendo como base a Resolução nº 196/96. Após receber parecer favorável à realização da pesquisa, entrou-se em contato com a diretoria da instituição escolhida, onde os pesquisadores apresentaram-se com uma carta contendo os objetivos e a importância do desenvolvimento da pesquisa. Um termo de consentimento livre e esclarecido foi assinado pela diretora já que a mesma é responsável pelos alunos no ambiente escolar. M ediante 0 aval da referida instituição, realizou-se um rastreamento, através do BDI, para a delimitação da amostra composta por crianças e adolescentes que apresentam a sintomatologia depressiva. Os pré-requisitos para a composição da amostra foram: a) aceitar participar do estudo; b) estar cursando regularmente o ensino médio; c) ter idade mínima de quatorze anos e máxima de dezenove anos; d) apresentar resultados, no BDI, acima do ponto de corte (17); e) não apresentar outros sintomas de psicopatologia. Em seguida, os adolescentes constituintes da amostra foram submetidos à associação livre de palavras e, em seguida, às entrevistas individualmente em salas adequadamenteescolhidas nos estabelecimentos de ensino. Os dados foram registrados através do gravador em sessões sem tempo delimitado.

\section{Análise dos dados}

Os dados da associação livre de palavras foram processados pelo software Tri-deux-M ots ${ }^{23}$ e analisados por meio da Análise Fatorial de Correspondência (AFC). A AFC consiste em destacar eixos que explicam as modalidades de respostas, mostrando estruturas constituídas de elementos do campo representacional, o que permite representar graficamente a tração entre as variáveis fixas neste estudo (sexo, série e idade), e as variáveis de opinião, que correspondem às palavras evocadas pelos participantes. Deste modo, as primeiras encontram-se em colunas e as últimas são linhas constituídas por palavras cruzadas pelo softwareTri-deuxM ots e revelam a dinâmica de atração e distanciamento entre as modalidades de respostas e características dos grupos. Os dados do BDI foram somados para identificar o escore mínimo (17 pontos).

Os dados coletados por meio das entrevistas foram codificados pela análise de conteúdo temática ${ }^{24}$, que visa obter, por procedimentos sistemáticos e objetivos de descrição do conteúdo das mensagens, indicadores que permitem a inferência de conhecimentos relativos às condições de produção/recepção (variáveis inferidas). Os dados das entrevistas também foram analisados quantitativamente por meio de análises estatísticas descritivas. Foi utilizado o critério de saturação proposto por Sá25 no processo de análise e construção das categorias empíricas; desta forma, a análise é interrompida quando os conteúdos passam a se repetir seguidamente, sem que novos temas sejam observados no discurso dos atores sociais.

\section{Resultadosediscussão}

No Gráfico 1, serão apresentados os dados referentes ao teste de associação livre de palavras, acerca das representações sociais da depressão apreendidas em adolescentes no contexto do ensino médio. Estas representações foram construídas tendo por base os estímulos indutores (depressão, pessoa deprimida e eu mesmo) e analisadas por meio do software Tri-deux-M ots, desenvolvido por $\mathrm{Ci}$ bois $^{23}$. O gráfico oferece uma representação das variações semânticas na organização do campo espacial, no qual ilustra aproximações e oposições 
das modalidades na construção dos fatores (F1 e postas, sendo que o F1 apresentou 36,3\% e o F2, F2). Os dois fatores foram detentores de um po- $\quad 27,9 \%$, possuindo, portanto, parâmetros estatísder explicativo de $64,2 \%$ da variância total de res- ticos com consistência interna efidedignidade.

F2

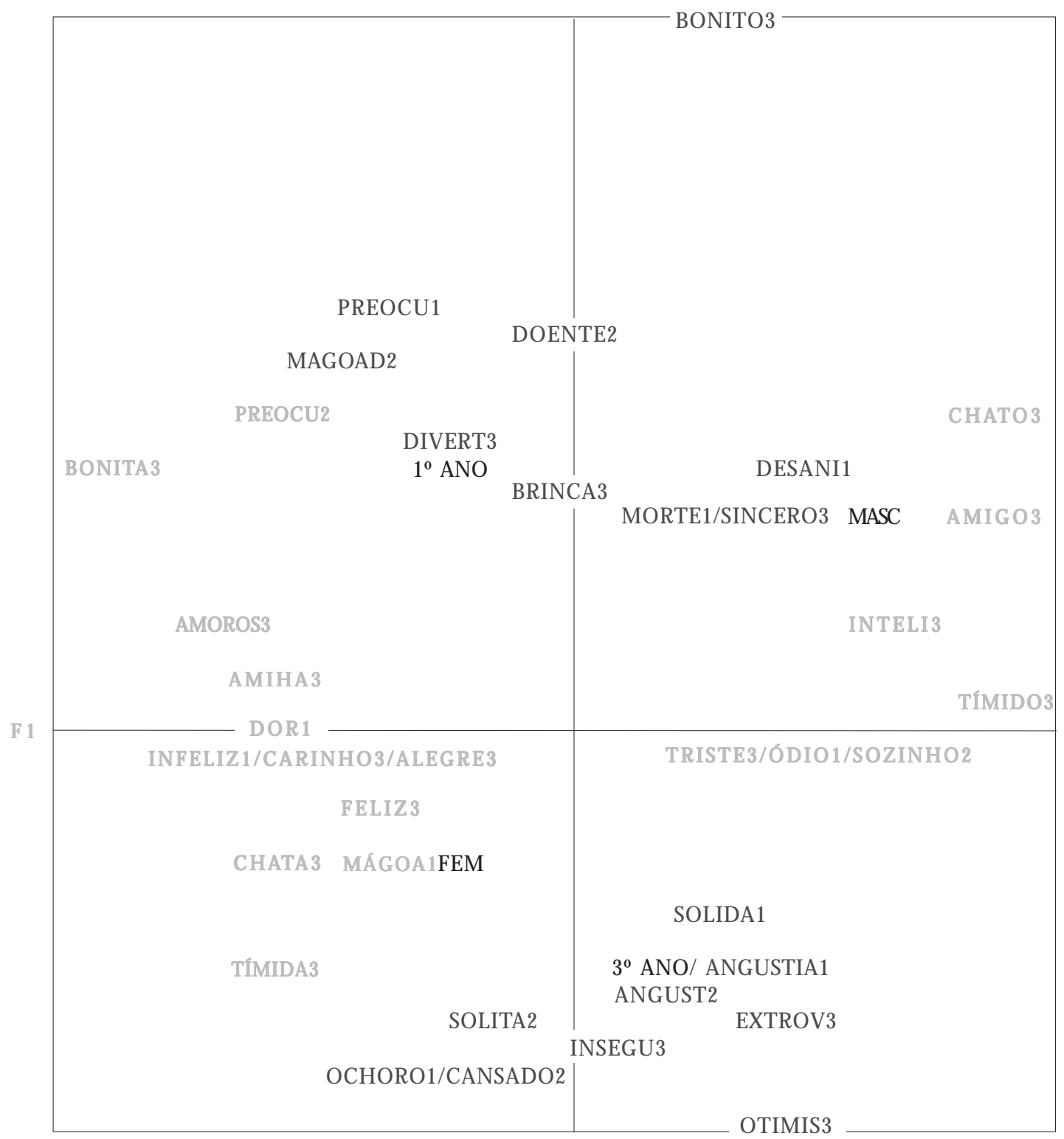

Legenda

F1 (Eixo N egativo) = Cor cinza claro, horizontal

F2 (Eixo Positivo) = Cor cinza escuro, vertical
Estímulos

1. Depressão

2. Pessoa deprimida

3. Eu mesmo
Variáveis fixas

Sexo - 1. Masculino/2. Feminino

Idade - 1. 14-16/ 2. 17-19

Série - 1. 1aㅡ serie/ 2. 2aㅡ serie/ 3. 3äserie

Gráfico 1. Plano fatorial de correspondência das representações sociais da sintomatologia da depressão em adolescentes. 
O gráfico destaca com clareza dois campos semânticos configurados em oposição sobre o fator F1. No eixo da esquerda, em negrito, encontramse aglomeradas as representações que caracterizam o grupo dos adolescentes do sexo feminino. Para este grupo, a depressão é representada como dor, mágoa, infelicidade. Elas vêem uma pessoa deprimida como preocupada e a si mesmas como bonitas, amorosas, alegres, chatas e tímidas. Inversamente, nesse mesmo fator à direita, configurase o campo semântico elaborado pelos adolescentes do sexo masculino, em que os mesmos associam a depressão ao elemento ódio, a pessoa deprimida é vista por eles como uma pessoa sozinha e, quanto a si mesmos, surgiram elementos como triste, tímido, inteligente, amigo e chato.

Com relação ao fator $F 2$, linha vertical, em itálico, os grupos de adolescentes encontram-se diametricamente distanciados, o que indica discordâncias representacionais. Na margem superior, localizam-seas representações dosadolescentesque cursam o primeiro ano; estes representam a depressão como preocupação, morte e desânimo. A pessoa deprimida é vista como doente e magoada. Representam a si mesmos com palavras tais como bonito, divertido, brincalhão e sincero. Na margem inferior, destacam-se as modalidades representacionais dos adolescentes pertencentes ao terceiro ano, que representam a depressão como angústia, solidão e choro. Para representar uma pessoa deprimida, usam palavras como angustiada, solitária e cansada. Para si mesmos, elaboraram palavras como inseguro, extrovertido e otimista.

Esses resultados expressam que as representações sociais da depressão de adolescentes inseridos no contexto do ensino médio estruturam-se na interface da pluralidadee complexidade do funcionamento de elementos afetivos, mentais, sociais, cognitivos e comportamentais com o contexto psicossocial no qual se encontram inseridos. Sob esse aspecto, o sentido que essa sintomatologia adquirenos processos interacionais émarcado pela consensualidadena medida em que, independentemente das diferenças individuais e/ou de grupos, a de pressão é representada pelos elementos figurativos "tristeza" e "morte".

Observa-se nesses dados que a etiologia da depressão é predominantemente vista como sendo proveniente de fatores psicossociais, tais como a mágoa, o ódio e as preocupações que podem advir de fatores sociais. Nesse sentido, Coutinho afirma que a depressão possui, em sua etiologia, uma série de fatores que podem estar relacionados a aspectos psicológicos, socioculturais efisiológicos.
Os sintomas depressivos na puberdade estão fortemente relacionados, dentre outros fatores, às adversidades no ambiente familiar. Os amigos servem como uma rede de apoio, na qual os jovens transferem para o espaço das solidariedades grupais as vinculações que na fase inicial da vida se estabeleciam apenas no interior do círculo doméstico ${ }^{8}$.

No que diz respeito à descrição da depressão, esta é vista como uma doença que provoca dor, infelicidade, desânimo, solidão e que pode levar à morte.

De forma consonante, Coutinho encontrou em seu estudo elementos psicoafetivos, tais como tristeza, carência afetiva, dor e solidão. A palavra tristeza é considerada como sinônimo de depressão e como a espinha dorsal, metáfora utilizada para explicá-la enquanto alicerce de toda a sintomatologia da depressão infantil. Corrobora-se também através desta autora que a depressão emerge de forma indissociável entre o objeto (depressão) e o sujeito (ser depressivo), constatada nas representações dos atores sociais deste estudo.

No que diz respeito à solidão, Dultra ${ }^{10}$ afirma que os sintomas depressivos se manifestam entre os adolescentes de maneira específica onde ocorrem alterações no comportamento tais como isolamento, rebeldia, agressividade e irritabilidade.

A dor é geralmente associada à depressão no conhecimento elaborado pelo senso comum onde esta é vista como uma forma de expressão do sofrimento da dor humana. As diferenças emergem à medida que se articulam as características dos indivíduos que a representam e a inserção social dos mesmos 5 . A depressão pode interferir de maneira significativa na vida diária, nas relações sociais e no bem-estar geral do adolescente, podendo até levar ao suicídio. As falas dos atores sociais corroboram com Cordás ${ }^{26}$ quando o mesmo destaca que a depressão é uma doença que afeta todo o organismo, inclusive o pensamento.

Pensar repetitivamente em morrer é sinal de quea vida está produzindo um desprazer geral tão intenso queaúnica forma de aliviá-lo émorrendo. Coutinho ${ }^{1}$ afirma que, segundo os dados da epidemiologia psiquiátrica, a atração por pensamentos de suicídio ou de morte é quase uma constante na constelação dos sintomas depressivos, sendo 0 suicídio mais comum nas depressões endógenas, ansiogênicas e severas.

O DSM -IV V considera o sentimento de desânimo como um dos componentes apresentados pela sintomatologia depressiva em adolescentes, fato esteencontrado nas representações dos adolescen- 
tes desse estudo, que indicam uma ligação deste sintoma a uma diversidade de sentimentos e sensações que imprimem uma maneira peculiar de vivenciar e sentir os eventos da vida.

Com relação à auto-percepção, surgiram elementos positivos assim como negativos em ambos os grupos. No que diz respeito aos aspectos positivos, as adolescentes se percebem como amorosas, alegres e bonitas; já os adolescentes se percebem como inteligentes e amigos. Observa-se através desses dados que tanto as adolescentes quanto os adolescentes atribuem características positivas socialmente desejáveis e esperadas em função do sexo a qual cada grupo pertence (meninas e meninos).

Já em relação aos aspectos negativos, não houve uma diferenciação em relação ao sexo; tanto os adolescentes quanto as adolescentes se perceberam chatos, tímidos e tristes. A construção negativa da auto-imagem se configura como representante de um estado psicológico, com atividades cognitivas impregnadas de sintomatologia depressiva.

Em estudo realizado por Barros ${ }^{28}$, observouse uma tendência dos adolescentes com sintomatologia depressiva a expressarem uma percepção negativa desi mesmo, ou seja, sempre se percebendo como al guém desinteressante eincapaz de contribuir com algo positivo ou construtivo. Esse aspecto está intimamente relacionado a uma depreciação do eu causado pelo estado depressivo em queo indivíduo encontra-se numa relação patológica na qual existe uma ruptura ou distanciamento entre o eu real e o eu ideal ${ }^{29}$.

Ainda nesse sentido, alguns autores destacam a diferença entre a manifestação depressiva em adolescentes do sexo feminino e masculino, afirmando que as garotas relatam mais sintomas subjetivos, como sentimentos de tristeza, vazio, tédio, raiva eansiedade. Estas também costumam ter mais preocupação com a popularidade, menos satisfação com a aparência, mais conscienciosidade e menos auto-estima, enquanto que os garotos relatam mais sentimentos de desprezo, desafio e desdém, e demonstram problemas de conduta, tais como: falta às aulas, fugas de casa, violência física, roubos e abuso de substâncias ${ }^{30,} 31$.

No que diz respeito à prevalência na infância, a proporção da depressão em meninas e meninos é parecida, com a possibilidade de preponderância em meninos; porém, na adolescência, esta proporção se modifica, resultando na preponderância no sexo feminino, chegando ao dobro da observada no sexo masculino, principalmente após a puberdade, numa idade média entre 15 e 16 anos ${ }^{10,8}$.

As representações sociais acerca da depressão elaboradas pelos adolescentes incluídos no con- texto do ensino médio, com base no material coletado pelas entrevistas e ponderadas pela análise temática de conteúdo, resultaram em três (03) categorias empíricas evinte (20) subcategorias. Estas foram agrupadas por sua constituição temática de acordo com seu nível e grau de elaboração simbólica e estrutural, sendo nomeadas de acordo com suas características mais marcantes.

A primeira categoria, que se refere às concepções/descrições da depressão, subdividiu-se em oito subcategorias, conforme a Tabela 1. Os adolescentes descreveram a depressão com as seguintes palavras e proporções: tristeza (20\%), solidão (20\%), desânimo (19\%), choro (12\%), doença (12\%), morte ( $8 \%$ ), falta de apetite (5\%) e angústia (4\%).

Pode-se verificar nas falas a seguir: a pessoa deprimida é triste; algo triste, que ninguém quer passar; se sente sozinha, triste, solitária; me sinto deprimido, triste, com vontade de morrer e de chorar; a pessoa fica triste, sente vontade de morrer; a pessoa se sente distante dos outros; acho que depressão é doença; fica sem querer fazer nada, chorando, querendo se isolar; a pessoa fica com falta de apetite; as pessoas não conseguem se relacionar com as outras e ficam solitárias; é uma pessoa angustiada.

Nesta categoria, a depressão foi descrita deacordo com as representações dos atores sociais, sendo explicitado de forma abrangente o que eles sabem sobre depressão. N esse sentido, a depressão foi ancorada através de oito subcategorias como: tristeza, solidão, desânimo, choro, doença, morte, falta de apetite eangústia.

Quando se trata de depressão, é comum observar uma estreita ligação entre esta forma de psicopatologia e o sentimento detristeza, sendo esteconsiderado pela maioria dos estudiosos um sintoma

Tabela 1. Concepções/descrições da depressão.

\begin{tabular}{lcc}
\hline \multirow{2}{*}{$\begin{array}{c}\text { Categoria } \\
\text { e subcategorias }\end{array}$} & \multicolumn{2}{c}{ Adolescentes do ensino médio } \\
\cline { 2 - 3 } & $\mathrm{F}$ & $\%$ \\
\hline Tristeza & 26 & 20 \\
Solidão & 26 & 20 \\
Desânimo & 25 & 19 \\
Choro & 16 & 12 \\
Doença & 15 & 12 \\
M orte & 10 & 08 \\
Falta de apetite & 06 & 05 \\
Angústia & 05 & 04 \\
Total & 129 & 100 \\
\hline
\end{tabular}


da doença. No conhecimento do senso comum elaborado pelos adolescentes em questão, observouseuma significativa importância de tal conteúdo na construção da representação do fenômeno, visto que, no percurso de toda a elaboração do conhecimento, a tristeza foi constantemente evocada através do discurso dos sujeitos entrevistados.

Em pesquisa realizada por Barros ${ }^{28}$, pode-se apreender uma representação social da depressão ancorada, sobretudo, nos fatores relacionados à tristeza e à solidão entre os adolescentes secundaristas. Verificou-se também no discurso dos estudantes, comumente seguido de choros, uma aparente perda do sentido da vida como sinal de uma profunda tristeza, o que indica que para o saber da vida cotidiana, compartilhado por esses grupos, a depressão éo mesmo que uma tristeza causada por dores existenciais profundas. Infere-se que a tríade depressão - tristeza - solidão são sintomas fre qüentemente apresentados entre 0 conhecimento construído/elaborado por este grupo de pertença.

O DSM - IV ${ }^{27}$ ressalta a tristeza (humor deprimido) como um dos sintomas mais comuns ao estado depressivo tanto na adolescência como na fase adulta. Desta forma, o conhecimento prático corrobora com a visão científica da depressão e esclarece a importância desse sentimento no quese refere à identificação e manejo do quadro. Fato também observado por Coutinhoํㅣ em estudo com crianças que apresentam a sintomatologia depressiva, em que a tristeza foi identificada como um tópico de extrema importância na apreensão das representações sociais da depressão.

De forma semel hante às representações sociais verificadas entre os atores sociais desta pesquisa, Cruvinel e Boruchovitch ${ }^{32}$ salientam que a sintomatologia depressiva envolve uma gama de fatores, a saber: afetivos, cognitivos, comportamentais, motivacionais efisiológicos. Estas autoras ainda apontam que a sintomatologia depressiva pode contribuir para uma baixa no rendimento escolar nestes adolescentes; para isso, fazem-se necessárias intervenções que possam favorecer o uso de estratégias cognitivas, metacognitivas e afetivas para pode lidar melhor com as questões psicossociais e emocionais ocasionadas pela depressão.

As RS elaboradas pelos adolescentes pesquisados são influenciadas também pelos meios midiáticos, que veiculam comumente a pessoa depressiva que não possui ânimo, solidão e tristeza, bem como pelo fato da vivência destes sintomas na vida diária. Os meios de comunicação de massa e a difusão de saberes técnico-científicos transformam os modos de pensamento e elaboram conteúdos representacionais $s^{33}$.
A segunda categoria diz respeito às causas da depressão (Tabela 2) e foi subdividida em seis subcategorias: baixa auto-estima (37\%), problemas familiares (26\%), exclusão social (19\%), perdas (8\%), estresse (5\%) efalta de diálogo (5\%).

É válido mencionar quefoi verificado deforma bastantesignificativa entre os adolescentes problemas familiares eafetivos. Salienta-seque estas questões foram relatadas nos discursos dos atores sociais, não como algo característico da puberdade, como atitudes de rebel dia enão aceitação das normas estabelecidas no seio da família. Pode ser verificado nos discursos a seguir: briga na família, eu não gosto muito do meu pai; éexcluído da sociedade; não gosto de ser preto, as meninas só ficam com os caras brancos; eu não converso com meus pais; me acho feio, ridículo, estranho; eu noto que as pessoas me criticam; eu não gosto muito de conversar; eu não gosto da minha aparência física; depois que perdi meu pai, não sou maisfeliz; eu sou adotada, tenho vontade de conhecer meus pais de verdade; a pessoa estressada e sem dinheiro fica deprimida.

No entanto, foi verificado aspecto relacionado à falta de diálogo entre pais-filhos, casos de adultérios entre os pais que ocasionam discussões e por vezes atédivórcios, dificuldades econômicas ea utilização de bebidas alcoólicas pel os pais; estas questões são fatores importantes, que devem ser considerados como componentes predisponentes para possivel mente o surgimento da sintomatologia depressiva no adolescente. É necessário contemplar as questões relacionadas às diferenças regionais, econômicas e culturais da população brasileira que podem resultar em distintas apreen sões em investigações sobre sintomatologia depressiva ${ }^{34}$.

Tabela 2. Causas da depressão.

\begin{tabular}{lcc}
\hline \multirow{2}{*}{$\begin{array}{c}\text { Categoria } \\
\text { e subcategorias }\end{array}$} & \multicolumn{2}{c}{ Adolescentes do ensino médio } \\
\cline { 2 - 3 } & $\mathrm{F}$ & $\%$ \\
\hline Baixa auto-estima & 45 & 37 \\
Problemas familiares & 32 & 26 \\
Exclusão social & 23 & 19 \\
Perdas & 10 & 08 \\
Estresse & 06 & 05 \\
Falta de diálogo & 06 & 05 \\
Total & 122 & 100 \\
\hline
\end{tabular}


As questões concernentes ao surgimento de problemas relacionados à saúde mental na puberdade devem ser compreendidas também a partir do paradigma que rege o desenvolvimento de nossa sociedade, assim o processo de exclusão/inclusão social na adolescência é produto da marcante desigualdade de oportunidades existentes entre as classes sociais na realidade brasileira ${ }^{35}$.

0 apoio social e afetivo na idade escolar é importante para 0 adolescente com intuito de preservar a estrutura psíquica hígida para quesirva como mecanismo de defesa dos eventos traumáticos e estressantes na vida cotidiana ${ }^{36}$. Pode-se verificar entre os atores sociais desta pesquisa que foi bastante mencionado as causas relacionadas à fal ta de apoio psicossocial e exclusão/inclusão social como fatores predisponentes para o surgimento da sintomatologia depressiva.

Faz-se necessário que a psicologia social tenha como princípio básico a observância e escuta de modo a compreender com lucidez os fenômenos psicossociais tal como se encontram no mundo simbólico e significativo das pessoas e dos grupos 37, posto que os discursos dos adolescentes desta pesquisa permitem vislumbrar inferências condizentes às causas da depressão como problemas psicossociais/afetivos intrínsecos nas suas representações sociais.

Deste modo, os elementos que participam da construção ideológica e psicossocial, tendo a exclusão/inclusão social como um dos fatores que influencia diretamenteno surgimento da sintomatologia depressiva na adolescência, são determinados de certa maneira pelo paradigma dominante (sociedade capitalista e individualista), que influencia de forma direta nas representações sociais.

No que se refere à terceira e última categoria, formas de tratamento da depressão, conforme a Ta-

Tabela 3. Formas de tratamento da depressão.

\begin{tabular}{lcc}
\hline \multirow{2}{*}{$\begin{array}{c}\text { Categoria } \\
\text { e subcategorias }\end{array}$} & \multicolumn{2}{c}{ Adolescentes do ensino médio } \\
\cline { 2 - 3 } & $\mathrm{F}$ & $\%$ \\
\hline A poio sócio-afetivo & 43 & 43 \\
Tratamento psicológico & 21 & 21 \\
Apoio familiar & 18 & 18 \\
Pensamentos positivos & 10 & 10 \\
A poio religioso & 06 & 06 \\
Tratamento médico & 02 & 02 \\
Total & 100 & 100 \\
\hline
\end{tabular}

bela 3, houve a emersão de seissubcategorias: apoio sócio-afetivo (43\%), tratamento psicológico $(21 \%)$, apoio familiar ( $18 \%$ ), pensamentos positi$\operatorname{vos}(10 \%)$, apoio religioso (6\%) e tratamento mé $\operatorname{dico}(2 \%)$.

Como pode-se verificar nos discursos a seguir: pode ser tratada com acompanhamento psicológico; tentar pensar em coisas boas; tentar reconstruir a vida; procurar Deus e alguém pra conversar; fazer alguma terapia com um profissional; família pra ajudar, dar carinho e atenção; é preciso procurar a ajuda de médicos e psi cólogos; se tiver tratamento, conversar com outras pessoas.

Surgiram ainda representações acerca da cura da depressão; $93 \%$ dos atores afirmam que a de pressão tem cura e apenas $7 \%$ acham que a de pressão éincurável.

As representações sociais da depressão elaboradas pelos sujeitos da pesquisa foram dimensionadas a partir de categorias e subcategorias empíricas, agrupadas por sua constituição temática de acordo com seu nível e grau de elaboração simbólica e estrutural, sendo estas nomeadas de acordo com suas características mais marcantes.

Os grupos também apresentaram outra modalidade de tratamento, desta vez, ancorada na dimensão espiritual. Este é um exemplo de representações apoiadas em mitos e crenças no solo da cultura transmitidas entre gerações ${ }^{33}$, através das ideologias e instituições que perduram seus valores há tempos nas sociedades. É válido salientar que este componente espiritual também foi verificado entre idosos, fato que independe da fronteira de idades ${ }^{5}$.

Como forma de intervenção na sintomatologia depressiva em adolescentes, faz-se necessário que sejam priorizadas ações na saúde e na educação como áreas básicas para o desenvolvimento infanto-juvenil, com políticas abrangentes levando-seem conta a peculiaridade regional com seus costumes, crenças e dificuldades socioeconômicas ${ }^{38}$.

A partir desses resultados, percebe-se que ambos os grupos expressam mais de uma modalidade de tratamento, corroborando com as afirmações de Ballone ${ }^{11}$, quando este aponta que o tratamento dos sintomas depressivos deve se basear nos aspectos biológicos e psicossociais.

Evidenciou-se, neste estudo, que as representações sociais da sintomatologia depressiva elaboradas entre os adolescentes inseridos no contexto do ensino médio são construídas tendo como referencial a sua inserção psicoafetiva e socioeconômica, bem como pelos aspectos peculiares que permeiam a depressão nesta fase do desenvolvimento humano. 


\section{Consideraçõesfinais}

Ao se falar em depressão na puberdade, deve-se levar em consideração que esta fase da vida possui peculiaridades próprias do desenvolvimento, que indicam mudanças corporais, alterações hormonais, aumento da socialização, exercício edescoberta da sexualidade. Tais fatores exercem, naturalmente, uma coerção fundamental própria do exercício de novas experiências propiciadas pela maturação física e mental desses jovens. Em alguns casos, podem produzir uma desestabilização por vezes passageira; entretanto, quando cristalizadas na forma de sintomas depressivos, estão ligadas a sentimentos devastadores que são indicativos de um sofrimento patológico ${ }^{28}$.

Os atores sociais desta pesquisa descreveram a depressão com palavras como tristeza, solidão, desânimo, choro, doença, morte, falta de apetite e angústia. Identificaram com sendo as causas da depressão a baixa auto-estima, os problemas familiares, a exclusão social, as perdas, o estresse e a falta de diálogo. A grande maioria (93\%) afirmou que a depressão tem cura e esta se dá através de apoio sócio-afetivo, tratamento psicológico, apoio familiar, pensamentos positivos, apoio religioso e tratamento médico.

As representações sociais da depressão revelaram algumas semelhanças em relação ao conhecimento científico sobre 0 assunto ${ }^{39}$. A pluralidade e a complexidade dadas aos sintomas da depressão pela ciência foram reproduzidas pelo conhecimento prático da maioria dos adolescentes. Dor, mágoa, infelicidade, ódio, preocupação, morte, desânimo, angústia, solidão e choro são elementos que se destacam na articulação do pensamento destes atores sociais.

O bservou-se que no campo da consensualidade a depressão na puberdade foi representada por palavras eidéias que a caracterizam como uma doença altamente debilitante, que pode causar privação social, prejuízos funcionais, sofrimento psicológico, mudanças de comportamentos e levar à morte. N este sentido, faz-senecessário quea tríadeescola família - educadores possa contribuir para proliferação de mecanismos de prevenção primária a depressão no contexto escolar, bem como disponibilize a inserção de profissionais psicólogos escolares e psicopedagogos para um diagnóstico precoce destas patologias psicossociais e futuras intervenções na saúde mental destes adolescentes.

A literatura com enfoque psicossocial da depressão em adolescentes apresenta-seescassa, o quesugere que outras pesquisas sejam realizadas a fim de oferecer alternativas para a elaboração de intervenções preventivas em saúde coletiva tendo com alvo adolescentes, de modo que possa verificar como é elaborada a sintomatologia da depressão no nível cognitivo, observar como esta representação é partilhada por esses indivíduos, como eles transformam o não inteligível em inteligível para os membros do grupo, possibilitando uma interação social integrada.

\section{Colaboradores}

M PL Coutinho orientou a elaboração do artigo; TA Aragão, LF Araújo e AR Castanha participaram de todas as outras etapas. 


\section{Referências}

1. Coutinho MPL. Depressão infantil: uma abordagem psicossocial. João Pessoa: UFPB; 2001.

2. Nascimento I. Depressão unipolar: uma revisão. Revista Informação Psiquiátrica 1999; 18(3); 75-83.

3. Lafer B, Amaral JAMS. Depressão no ciclo da vida. Porto Alegre: Artes M édicas; 2000.

4. Widlöcher D, Hardy MC. La dépression. Paris: Overture M edicale; 1991.

5. Coutinho MPL, Araújo LF, Sá RCN. Depressão um sofrimento sem fronteira: representações sociais entre crianças e idosos. Psico USF 2003; 8:183-192.

6. Winnicott D. 0 brincar e a realidade. Rio de Janeiro: Imago; 1993.

7. Baptista M N, Baptista ASD, Dias RR. Estrutura e suporte familiar como fatores de risco na depressão de adolescentes. Psicol. cienc. prof. 2001; 21(2):52-61.

8. Duggal S, Carlson EA, Sroufe A, Egeland B. Depressive Symptomatolology in Childhood and Adolescence. Development and psychology. Cambridge: Cambridge University Press; 2001.

9. Kazdin $\mathrm{AE}, \mathrm{M}$ arciano PL. Childhood and Adolescent Depression. In: M ash E, Barkley R, editors. Treatment of childhood disorders. New York: The Guilford Press; 1998. p. 231-258.

10. Dultra SEM. Depressão e suicídio em crianças e adolescentes. M udanças Psicoterapia e estudos Psicossociais 2001; 9(15):27-35.

11. Ballone G]. Depressão na adolescência. PsiqWeb [site na Internet]. Disponível em: http://www.psiqweb. med.br/http://sites.uol.com.br/gballone/infantil/ adolesc2.html

12. Resmini E. A tentativa de suicídio na adolescência. In: Granã R. Técnicas psicoterápicas na adolescência. Porto Alegre: Artes Médicas; 1984.

13. Doise W. Les representations sociales. In: Ghiglione R, Bonnet C, Richard JF, editeurs. Traité de Psychologie Cognitive. Paris: Dunod; 1990

14. Moscovici S. A representação social da psicanálise. Rio de Janeiro: Zahar; 1978.

15. Poznanski EO. Affective disorder. In: Michels R, editor. Psychiatry. Philadelfia: Lippincott Company; 1993. p. 1-9.

16. Palacio EF, Dufour R. Diagnostic structurel chez I' enfant. Paris: Masson; 1995.

17. Angold A, Costello EJ. The epidemiology of depression in children and adolescents. In: Goodyer IM, editor. The depressed child and adolescent: developmental and clinical perspectives. Cambridge: Cambridge University Press; 1995. p. 127-147.

18. Beck AT. Inventory For M easuring Depression. Archives of General Psychiatry 1961; 4:561-571.

19. Gorenstein C, Andrade L. Inventário de depressão de Beck: propriedades psicométricas da versão em português. Rev. Psq. Clín.1998; 25(5):245-250.

20. Anzieu D. La psychanalyse au service de la psychologie. N ouvelle Revue de Psychanalyse 1979; 20:59-75.

21. De Rosa AS. Sur l'usage des associations libres dans I'étude des représentations sociales de la maladie mentale. Rome: Université de Rome; 1988.
22. Abric JC. Pratiques sociales et représentations. Paris: Presses Universitaires de France; 1994.

23. Cibois UFR. Tri-deux-mots. Versão 1.1. Paris: Sciences Sociales; 1990

24. Bardin L. Análise de conteúdo. Lisboa: Edições 70; 2002.

25. Sá CP. A construção do objeto de pesquisa em representações sociais. Rio de Janeiro: UERJ; 1998.

26. Cordás T. A depressão da bile negra aos neurotransmissores uma introdução histórica. São Paulo: Lemos; 2002.

27. American Psychiatric Association. Diagnostic and statistical manual of mental disorders. DSM -IV. $4^{\text {th }} \mathrm{ed}$. Washington, D.C.: American Psychiatric Association; 1994.

28. Barros APR. Coutinho, M PL, Araújo, LF, Castanha, AR. As representações sociais da depressão em adolescentes no contexto do ensino médio. Estudos de Psicologia da PUCCAM P 2006; 23(1):19-28.

29. Carvalho AC. Depressão: doença do corpo e da alma. Psychê 2000; 4:62-45.

30. Sadler LS. Depression in adolescents. Context, manifestations, and clinical management. N urs Clin N orth Am 1991; 26:559-572.

31. Baron P, Campbell TL. Gender differences in the expression of depressive symptoms in middle adolescents: an extension of early findings. Adolescence 1993; 28(112): 903-911.

32. Cruvinel M, Boruchovitch E. Depressão, estratégia de aprendizagem escolar. Psicologia em Estudo 2004; 9(3):369-378.

33. Moscovici S. Representações sociais: investigações em psicologia social. Petrópolis: Vozes; 2003.

34. Pérez MV, Urquijo S. Depresión en adolescentes. Relaciones con el desempeño académico. Psicologia Escolar e Educacional 2001; 5(1):49-58.

35. Circe MNR, M ello TKS. A política de atendimento à criança e ao adolescente no Brasil. In: Alberto M FP, organizador. Crianças e adolescentes que trabalham: cenas de uma realidade negada. João Pessoa: EdUFPB; 2003. p. 237-241.

36. Pekrun R, Goetz T, Titz W, Perry RP. Academic emotions in students self-regulated learning and achievement: a program of qualitative and quantitative research. Educational Psychologist 2002; 37(2):91-105.

37. Guareschi P. Psicologia social crítica: como prática de libertação. Porto Alegre: EDIPU CRS; 2004.

38. Frota MGC. A cidadania da infância e da adolescência. In: Carvalho A, Salles F, Guimarães M, Ude W, organizadores. Políticas Públicas. Belo Horizonte: EdUFM G; 2003. p. 59-85.

39. Jodelet D. Les representations sociales. Paris: PUF; 1989.

Artigo apresentado em 14/05/2007

Aprovado em 23/11/2007 